\title{
DISPUTAS PELA BASE NACIONAL COMUM CURRICULAR: PENSANDO EM DIFERENÇA E EM EDUCAÇÃ̆O
}

Adriano Vargas Freitas William de Goes Ribeiro ${ }^{(*)}$

A defesa de que precisamos produzir um documento curricular "inovador" como um elemento indispensável para atingirmos a "qualidade educacional" vem se dando por meio de um exterior que lhe é constitutivo: crise da educação, professores malformados, incompetência do Estado na administração pública etc. (MACEDO, 2014). Nessa configuração discursiva, atribui-se uma projeção salvacionista para o currículo, entendido como um produto, que em "um novo formato" irá supostamente garantir os "direitos de aprendizagem e desenvolvimento" dos alunos por intermédio da definição de "conteúdos mínimos".

Esta não é uma discussão nova no Brasil, já que remonta a disputas políticas antigas que culminaram inclusive na sua inclusão na Constituição Federal de 1988, conforme destaque a seguir que orienta futuros passos para a organização do sistema de ensino em nosso país.

Art. 210. Serão fixados conteúdos mínimos para o ensino fundamental, de maneira a assegurar formação básica comum e respeito aos valores culturais e artísticos, nacionais e regionais.

$\S 1^{\circ}$. O ensino religioso, de matrícula facultativa, constituirá disciplina dos horários normais das escolas públicas de ensino fundamental.

$\S 2^{\circ}$. O ensino fundamental regular será ministrado em língua portuguesa, assegurada às comunidades indígenas também a utilização de suas línguas maternas e processos próprios de aprendizagem. (...)

Art. 211. À União cabe organizar o sistema federal de ensino, financiar as instituições de ensino federais e exercer, em matéria educacional, função redistributiva e supletiva, para garantir equalização de oportunidades educacionais e padrão mínimo de qualidade do ensino mediante assistência técnica e financeira aos estados, ao Distrito Federal e aos municípios. Os municípios devem atuar prioritariamente no ensino fundamental e na educação infantil, os estados e o Distrito Federal, prioritariamente nos ensinos fundamental e médio. (BRASIL, 1988, p. 20).

\footnotetext{
${ }^{(*)}$ Adriano V. Freitas. Doutor em Educação Matemática pela Pontifícia Universidade Católica de São Paulo (PUC-SP). William de Goes Ribeiro. Doutor em Educação pela Universidade Federal do Rio de Janeiro (UFRJ).
} 
Desde este período de redemocratização no país, a proposta vem sendo retomada, hoje mais incisivamente, por uma austera e astuta retórica que defende a implantação de uma "Base Nacional Curricular Comum" (BNCC), no sentido de uma "lista de competências e de conteúdos específicos" para a prática docente. Dentre os argumentos apresentados para que essa Base, compreendida desta forma, seja necessária e indispensável, remobiliza-se a corrente ideia da busca por uma pseudo unidade nacional, a qual regulará os currículos. Entretanto com poucos espaços para questões prementes como cultura e diferença.

Importante que se destaque também o Plano Nacional de Educação (PNE) vigente para o período de 2014 a 2024, que lista entre as suas metas a implementação de proposta de "direitos e objetivos de aprendizagem e desenvolvimento" (BRASIL, 2014, p. 21) que configurarão a Base Nacional Comum Curricular para toda a educação básica de nosso país. Entretanto, ressalta-se o espaço dado neste documento para o incentivo a práticas curriculares envolvendo abordagens interdisciplinares (p.53), ampliação do diálogo entre teoria e prática, articulações dos conteúdos a diferentes dimensões (ciência, trabalho, linguagens, tecnologia, cultura e esporte), atenção à formação do professor que "implementará" tais currículos, entre outros pontos que parecem estar sendo minimizados em atuais propostas.

Diversas instituições ligadas a estas questões, tais como a Associação Nacional de Pesquisadores em Educação (ANPEd) e a Associação Brasileira de Currículo (ABdC), por exemplo, vem promovendo encontros entre pesquisadores de diversas áreas para discutir estes pontos. As referidas instituições têm promovido, ademais, campanhas mobilizando professores e pesquisadores de todo o país, como a intitulada: "Aqui já tem currículo!"1, provocando a necessidade de uma base centralizadora desta natureza. Recentemente, um documento produzido por ambas foi enviado ao Conselho Nacional de Educação (CNE) como uma carta manifesto, listando os motivos contra uma $\mathrm{BNCC}^{2}$. Assim como neste projeto, temos encontrado muitas articulações em defesa de maior clareza dos currículos, da padronização e da objetividade a respeito do que deve ser ensinado nas escolas, buscando ampliar o debate e incluir mais profissionais da área da Educação.

Mas, mudanças no cenário político do país tem tentado minar estes debates e indicam que as propostas de centralização curricular estão "sob nova direção" (FREITAS, 2016). O curso histórico parece estar permitido sobressair uma força conservadora crescente no exercício do poder. Por

\footnotetext{
${ }^{1} \mathrm{O}$ projeto tem coletado depoimentos escritos e em vídeo de profissionais da educação de todo o país. Endereço na internet: 〈http://www.anped.org.br/campanha/curriculo〉. Acesso em 28/05/2018.

${ }^{2}$ Cf. 〈http://www.anped.org.br/sites/default/files/resources/Of_cio_01_2015_CNE_BNCC.pdf>. Acesso em 28/05/2018.
} 
intermédio de tal configuração, o movimento "Escola Sem Partido" vem defendendo publicamente a BNCC, questionando severamente as duas versões anteriores ${ }^{3}$. Nesta disputa, estão tomando uma série de medidas ${ }^{4}$ contra uma gestão democrática, visando influenciar a ação de pais e alunos através da cultura da delação contra "os ideólogos”, sobretudo, os professores da escola básica, supondo que boa parte deles impõe uma ideologia partidária aos seus alunos, os quais têm sido tratados pelos defensores deste movimento como "audiência cativa".

Considerando o exposto, o objetivo do atual estudo é debater a retórica problemática contida na ideia de uma BNCC entendida como "uma lista específica de competências e de conteúdos", bem como destacar as ameaças ao sentido democrático que vínhamos obtendo até então. Em um primeiro momento, salientamos alguns sentidos que vem sendo atribuídos à BNCC e ao currículo. Posteriormente, a ênfase do estudo recai sobre os riscos de uma centralização curricular e de como eles vem sendo perceptíveis a partir do "Movimento Escola Sem Partido" (MESP). A partir disso, tecemos algumas considerações, distante da ideia de uma conclusão e/ou ponto final.

\section{BNCC, PARA QUEM? DIREITOS DE APRENDIZAGEM E DE DESENVOLVIMENTO, PARA QUEM?}

$\mathrm{Na}$ atual seção deste estudo, destacamos alguns dos sentidos de BNCC, de currículo, de direitos de aprendizagem e de desenvolvimento que estão sendo articulados nos contextos políticos no Brasil, bem como os sujeitos em destaque nesse cenário tão controverso. $\mathrm{O}$ argumento é que não há um sentido único e absoluto para cada um dos citados significantes, mas que eles são efeitos dinâmicos de relações de poder cujos embates se dão reiteradamente.

Nesta produção vamos nos referir a currículo como uma arena processual de disputas justamente pelo que vem a ser currículo, ou seja, um campo de discussão específico em que distintas finalidades educativas entram em confronto (LOPES e MACEDO, 2011). Portanto, a questão curricular é complexa e envolve múltiplos contextos, conforme as referidas autoras enfatizam:

Indo dos guias curriculares propostos pelas redes de ensino àquilo que acontece em sala de aula, currículo tem significado, entre outros, a grade curricular com disciplinas/ atividades e cargas horárias, o conjunto de ementas e os programas das disciplinas/ atividades, os planos de ensino dos professores, as experiências propostas e vividas pelos alunos (p. 19).

\footnotetext{
${ }^{3}$ Por exemplo, cf. <https://www.youtube.com/watch?v=-YjSBI9nNY8>. Acesso em: 18/04/17.

${ }^{4}$ Cf. <www.escolasempartido.com.br>. Acesso em: 18 abr. 17.
} 
Em nossa perspectiva, trata-se de uma prática de significação que visa fixar sentidos sobre currículo, tornando-os hegemônico pela definição do que deve ou não ser objeto educacional, de ensino e de aprendizagem, projeto este levado a cabo por uma organização e/ou uma instância educativa. Para Laclau (2009), hegemonia é quando um sentido particular preenche o lugar da totalidade. Assim, os sentidos particulares buscam a hegemonia, sendo a abertura da linguagem ou a impossibilidade do fechamento o movimento que gera o jogo político. Nessa abordagem discursiva, como a totalidade não é possível, sempre há antagonismos no processo - que em tal perspectiva lhe é constitutivo. Desta forma, não há e nem nunca houve um único sentido de currículo em jogo, como também não há universalidade para os sentidos de BNCC, de comum, de nacional e de direitos de aprendizagem e de desenvolvimento. Se sentidos particulares estão sempre em disputa na política, questionamos: O que se entende por BNCC? A quem interessa uma BNCC? Que sentidos de currículo vêm sendo articulados nesta política? Estabelecer o mínimo garante qualidade de educação? O que é uma educação de qualidade? Base é uma lista de conteúdos? Nacional, para quem? Comum, para quem?

Pesquisadores de diversas áreas destacam a complexa relação público-privada nos dias atuais. Nela, identificamos um conjunto de medidas e propostas que podemos denominar de neoliberal, a qual tem dado visibilidade a determinados sujeitos, entendendo que em uma perspectiva discursiva os sujeitos não pré-existem às demandas ${ }^{5}$. Nesse sentido, Ball (2014) analisa como uma rede complexa (ou uma "comunidade política") a inserção de órgãos privados em parceria com setores públicos no campo da educação. Trata-se de articulações tecidas a partir da busca de resolução de determinados problemas, o que performatiza a ideia de reforma, projetando “identidades" para se adequarem à agenda global, cujo sentido depende, necessariamente, da tríade currículo, formação docente e avaliação.

$\mathrm{Na}$ esteira do referido autor, Macedo (2014) destaca parte da rede política em torno da BNCC no Brasil: Instituições financeiras e empresas (Itaú/Unibanco; Bradesco; Santander; Gerdau; Natura; Volkswagen, entre outras), além da Fundação Victor Civita; Fundação Roberto Marinho; Fundação Lemann; CENPEC; Todos pela Educação; Amigos da Escola. Conforme salienta a pesquisadora e o próprio Ball, a demanda em torno de soluções para a "crise da educação" articula instituições filantrópicas, grandes corporações financeiras que deslocam impostos para as suas

\footnotetext{
${ }^{5}$ Assim como Macedo (2014), entendemos que a nomeação dos sujeitos se dá como uma opção diante da tentativa de entendê-los como constituídos no processo. Dessa forma, compartilhamos da visão que sujeitos são constituídos na ação política de maneira contingencial. Em outras palavras, não estamos tratando de uma identidade prévia a partir da qual defendem uma posição única e/ ou absoluta.
} 
fundações, produtores de materiais educacionais vinculados ou não às grandes empresas internacionais do setor.

Atrelado à cultura da "testagem" (MILLER, 2014) das avaliações em larga escala e das políticas accountibility, o sentido de "comum" da BNCC ignora processos democráticos e cria uma sociabilidade que coloca "para fora" o imponderável da educação (MACEDO, 2014). A busca obsessiva por resultados, estes impregnados pela suposta neutralidade e pela frieza dos índices comparativos, configura uma perspectiva de currículo que reduz a complexidade do campo. Tal discurso articula um processo metonímico de currículo quando o reduz a objeto, a produto, a lista de conteúdos pré-dados, a normatividade, a obrigação, a mesmice, a mínimo, a regulação, a controle.

Sobre a questão, Garcia e Fontoura (2015) salientam: o que tem sido comum é uma história de invisibilização do outro e da diferença a partir de elementos considerados (enquanto conhecimentos) mínimos, associados a saberes que são pretensamente universais. O sentido de comum em questão é suposto por um "nacional” que o antecede e o define. Alertam pesquisadores, a mudança aparentemente sutil de "Base Comum Nacional" para "Base Nacional Comum", aparecendo pela primeira vez na LDB/96, não é um mero jogo de palavras (ALVES, 2014; GARCIA; FONTOURA, 2015). Em tal perspectiva, é uma "identidade nacional” com um sentido particular e pretensamente único de "nação" que determina o que é comum. Deste modo, a diferença permanece submetida à similaridade de uma igualdade formal e homogeneizadora. $\mathrm{O}$ sentido se desdobra para uma BNCC:

Na BNCC, a tendência proposta para a formação humana é a modelizacão, a homogeneização por meio da acentuação dos processos de administração centralizada, ignorando as "realidades locais", suas especificidades, possibilidades e necessidades, buscando produzir identidades serializadas e eliminando as diferenças. Há uma formula estreita: um triângulo em cujos vértices estão a BNCC, a formação de professores e a avaliação em larga escala, estruturadas a partir de 4 objetivos de formação: competência, qualificação profissional, empregabilidade e avaliação de desempenho. Resultado: padronização e eliminação da diferença ou do diferente em seus direitos à singularidade. (ANPED, 2016, p. 2).

Macedo (2014) salienta os seguintes sentidos que vem sendo articulados como BNCC: "conteúdos"; "expectativas de aprendizagem"; “direitos de aprendizagem"; "padrões de avaliação". Em tal configuração, a abordagem histórico-crítica de Demerval Saviani e os trabalhos recentes do sociólogo Michael Young tem tido relevante notoriedade (MACEDO, 2015). Deste modo, 
questiona a referida autora, a defesa realista e essencialista de que há "conhecimentos universais" ou "poderosos" e que a partir deles os currículos deveriam ser definidos permite fácil adesão quando articulados a esfera de direitos de aprendizagem, encontrando ressonância no discurso pedagógico.

É claro que não se trata de negar direitos e nem qualidade - esta questão muitos de nós compartilhamos - mas a questão é: de que direitos de aprendizagem estamos tratando? Estariam eles em consonância com a perspectiva democrática se forem definidos previamente?

Para Garcia e Fontoura (2015), os discursos em torno da BNCC promovem um esvaziamento da expressão "direitos de aprendizagem”, uma vez que os direitos se reduzem a conteúdos e habilidades pré-dadas, com uma ênfase recente na reedição regulatória das competências gerais e específicas, a serem alcançadas pelos professores no desenvolvimento do seu trabalho com os alunos. Considerando que "o mínimo" se torna "o máximo" em uma política de resultados, conforme discutem Oliveira e Pereira (2014) a partir das experiências com a centralização curricular na rede Estadual do Rio de Janeiro, as ações docentes e discentes estarão pressionadas por instrumentos regulatórios de gestão. Em outras palavras, o que vale é o que "cai na provinha" (GARCIA; FONTOURA, op. cit.). Nesse sentido, "diferença" se restringe ao tal "respeito à diversidade" - o qual ocupa hoje um "lugar comum" nas disputas em discursos distintos, independente das tendências políticas, sejam elas liberais, conservadoras e/ou progressistas.

$\mathrm{Na}$ busca de revestir em maior credibilidade a proposta da BNCC, seus idealizadores (e seus apoiadores, anteriormente citados) abriram um espaço de contribuições na página da internet ${ }^{6}$ sobre o tema, convidaram alguns pareceristas para analisarem as primeiras propostas (não são dadas informações de como selecionaram estes pareceristas) e elaboraram seminários de discussão. Entretanto, pouco se vê a respeito de como serão aproveitadas essas contribuições, visto que as novas versões pareceram não incorporar algumas importantes indicações encontradas, por exemplo, nos pareceres expostos neste ambiente. Interessante também destacar que uma rápida análise sobre as informações contidas na página nos permite conjecturar a inexistência de discussões mais aprofundadas entre seus próprios proponentes diretos, visto que, por vezes confundem em seus textos as ideias relacionadas à $\mathrm{BNC}$ e à $\mathrm{BNCC}$, assim como as próprias siglas. Isto se comprova na

\footnotetext{
${ }^{6}$ De acordo com informações expostas na própria página da BNCC, já teriam sido contabilizadas mais de 12 milhões de contribuições que teriam sido sistematizadas por pesquisadores da Universidade de Brasília (UnB) e da Pontifícia Universidade Católica do Rio de Janeiro (PUC-RJ). Endereço na internet: http://basenacionalcomum.mec.gov.br/aconstrucao-da-base. Acesso em: 18 abr. 2017.
} 
própria apresentação da página, conforme recorte abaixo, que buscaria responder à pergunta: $\mathrm{O}$ que é a BNCC?

A Base Nacional Comum Curricular (BNC) vai deixar claro os conhecimentos essenciais aos quais todos os estudantes brasileiros têm o direito de ter acesso e se apropriar durante sua trajetória na Educação Básica, ano a ano, desde o ingresso na Creche até o final do Ensino Médio. Com ela os sistemas educacionais, as escolas e os professores terão um importante instrumento de gestão pedagógica e as famílias poderão participar e acompanhar mais de perto a vida escolar de seus filhos. A Base será mais uma ferramenta que vai ajudar a orientar a construção do currículo das mais de 190 mil escolas de Educação Básica do país, espalhadas de Norte a Sul, públicas ou particulares. Com a BNC, ficará claro para todo mundo quais são os elementos fundamentais que precisam ser ensinados nas Áreas de Conhecimento: na Matemática, nas Linguagens e nas Ciências da Natureza e Humanas. A Base é parte do Currículo e orienta a formulação do projeto Político-Pedagógico das escolas, permitindo maior articulação deste. A partir da Base, os mais de 2 milhões de professores continuarão podendo escolher os melhores caminhos de como ensinar e, também, quais outros elementos (a Parte Diversificada) precisam ser somados nesse processo de aprendizagem e desenvolvimento de seus alunos. Tudo isso respeitando a diversidade, as particularidades e os contextos de onde estão. A Base é uma conquista social. Sua construção é crucial para encontrarmos um entendimento nacional em torno do que é importante no processo de desenvolvimento dos estudantes brasileiros da Educação Básica. Entender seu real significado e participar da sua construção é direito e dever de todos. (Disponível em: 〈http://basenacionalcomum.mec.gov.br/nota-oficial>. Acesso em: 18/04/17).

Este convite a entendermos seu "real significado" acaba se restringindo a acompanharmos outros textos e depoimentos de expoentes que defendem a construção e implementação de uma BNCC como, por exemplo, da sra. Nilma Fontanive, Integrante do Movimento pela Base Nacional Comum, para quem a adoção de uma base curricular comum seria fundamental para reduzirmos nossas desigualdades educacionais, e essencial para obtermos maior transparência sobre o que deve ser ensinado e aprendido, de acordo com critérios de qualidade. Esse processo geraria maior possibilidade de ser avaliado constantemente e geraria maior eficiência de nossas escolas. 


\section{O MOVIMENTO ESCOLAS SEM PARTIDO E AS DISPUTAS PELA BNCC}

Nesta seção do estudo, enfatizamos os sentidos de currículo que vem sendo articulados pelo Movimento Escola Sem Partido (doravante: MESP) em torno da BNCC. O argumento defendido é que tal operação de poder e de disputa ressalta os riscos de qualquer centralização curricular, isto é, torná-la uma lista de conteúdos específicos e uma finalidade para a mensuração dos resultados nas avaliações em larga escala, controlando a ação docente por intermédio de testes e resultados.

Nesse sentido, cabe salientar que a discussão a respeito da BNCC hoje está sob uma nova direção ${ }^{7}$ :

A nova equipe do MEC vai fazer uma "intervenção" no processo de condução da base nacional comum curricular e vai alongar a discussão nos Estados com vistas a terminar a base até o final do ano. O que conta agora são os seminários estaduais que deverão, a título de aprimoramento, gerar uma terceira proposta - ao sabor da nova equipe. (FREITAS, 2016, s/p).

Inaugurando um novo momento nesta disputa, parece ganhar fôlego uma força conservadora no exercício do poder no país. Nesse contexto, o jogo político permite maior visibilidade ao MESP. Cumpre lembrar que estamos lidando com a reelaboração de sentidos, antigos e novos, ao mesmo tempo. Mas, o que me chama a atenção é a centralidade "do currículo" no horizonte de interesses, tal qual uma lista de conteúdos - supostamente universais - para que os professores sigam ${ }^{8}$.

Assim, reedita-se tanto o realismo9 quanto a dicotomia "produção x implementação", questionáveis no campo do currículo, seja pelas questões teórico-metodológicas frágeis, seja pelos efeitos políticos que projetam professores e alunos como meros executores de conhecimentos produzidos pelos outros (LOPES; MACEDO, 2011).

Podíamos tecer outros debates a respeito deste movimento político, mas nos ocupamos com a política curricular, sem desconsiderar uma série de outras questões em curso que ameaçam os avanços que vínhamos tendo em uma direção mais democrática, por exemplo, a luta contra o racismo e contra a discriminação étnico-racial, de gênero, geracional, dentre outras demandas que elencamos doravante de maneira ampla como "demandas da diferença ${ }^{10}$ ".

\footnotetext{
${ }^{7}$ Cf. <https://avaliacaoeducacional.com/2016/05/31/bncc-sob-nova-direcao/>. Acesso em 10/04/17.

${ }^{8}$ Cf. <https://www.youtube.com/watch?v=-YjSBI9nNY8>. Acesso em: 10/04/17.

${ }^{9}$ Refere-se à crença na total independência ontológica do ser em relação à linguagem. Ou seja, as teorias são objetivas e neutras, permitindo acesso total e absoluto à realidade. Nesse sentido, o conhecimento científico é o espelho do real.

10 Quando nos referimos às demandas da diferença, não pretendemos reforçar a diferença como oposição à normalidade, favorecendo a normatização opressora e colonizadora; pelo contrário, tomamos a questão da diferença
} 
Conforme salienta o professor da Universidade Federal Fluminense Fernando Penna, o MESP não é novo. O citado pesquisador destaca em entrevista cedida à ANPEd que o movimento foi criado em 2004 pelo advogado Michel $\mathrm{Nagib}^{11}$, porém, vem ganhando visibilidade no conturbado momento político brasileiro, bem como espaços distintos de atuação em mídias diversas e projetos em andamento, alguns aprovados com extrema ligeireza.

Süssekind (2014) identifica - a partir de William Pinar e em diálogo com Boaventura de Sousa Santos- que as experiências norte-americanas com a centralização curricular tem gerado pelo corte da "linha abissal" (o que é ou não passível de ser ensinado) uma demonização do professor, pois este tem sido responsabilizado pelo suposto fracasso escolar quando, de fato, ele é responsabilizado por uma impossibilidade: a padronização da aprendizagem.

Tal questão, não é, indubitavelmente, a preocupação de deputados como Rogério Marinho um dos principais mobilizadores do MESP - uma vez que ele defende taxativamente que os professores sejam até mesmo avaliados pelo seu desempenho em exames, bem como responsabilizados pelos resultados dos alunos. Vislumbrando a terceira versão da BNCC, hoje homologada, defende o mérito como uma bandeira de luta. Seus projetos e discursos apresentam uma clara preocupação com o currículo, defendendo, inclusive, que decisões ligadas à BNCC não passem mais pelo Conselho Nacional de Educação, mas pelo Congresso Nacional, isso porque, para ele, é o espaço dos legítimos representantes do povo ${ }^{12}$.

Rogério Marinho é autor de vários projetos com enfoque no currículo e na educação. Em um deles, em tramitação, o deputado visa alterar a Lei 13.005 (PNE) para que determinados interesses políticos em torno da BNCC se efetivem, como dito antes, não mais passando por órgãos ligados à educação.

Por tal e evidente importância, é temerário que somente o Ministério da Educação (MEC) e o Conselho Nacional de Educação (CNE) sejam os responsáveis pela elaboração e aprovação da base. O processo em si mesmo já é condenável. Valoração tão importante para o futuro da nação deve ser amparada num processo democrático pelos poderes executivo, legislativo e comunidade educacional. (Disponível em <http://www.camara.gov.br/proposicoesWeb/prop_mostrarintegra;jsessionid=BEB1CB 63A318970E767BC84B2FCFC47C.proposicoesWeb1 ?codteor=1435263\&filename $=\mathrm{PL}$ +4486/2016>. Acesso em: 18/04/17).

como inerente ao discurso (BURBULES, 2012), isto é, toda enunciação é um ato de diferir, gerando sentidos que dependem, indubitavelmente, da interpretação do outro. Logo, abrindo o jogo político e as disputas de sentido.

${ }^{11}$ Disponível em: <http://www.anped.org.br/sites/default/files/images/anexo_i_oficio_anped_031_2016_entrevista com_fernando_de_araujo_escola_sem_partido.pdf $>$. Acesso em 10/04/17.

${ }^{12}$ Cf. https://www.youtube.com/watch?v=-YjSBI9nNY8. Acesso em 10/04/17. 
A máxima de que currículo é um campo de disputas talvez não tenha um exemplo mais simbólico no momento. Não obstante, o que desejamos enfatizar é que a abordagem curricular de cunho mais conservador não difere muito nem de um discurso neoliberal, tampouco do discurso crítico pedagógico em alguns aspectos importantes, uma vez que currículo também é pensado por eles como um objeto, um documento, como "uma arma" para mudar a educação, sobretudo porque compartilham da ideia de que há um conjunto de conhecimentos universais.

Retomando o enfoque da presente seção, considerando que o MESP defende a liberdade de expressão, mas é contrário à liberdade de ensino ${ }^{13}$, ensinar a história das culturas afro-brasileiras e indígenas na escola, recentemente impulsionadas pelas Leis 10.639/2003 e 11.645/2008, está ameaçado. Enfocar a luta contra o racismo e contra as desigualdades também pode se deslocar do espaço escolar, nesse sentido. Isso porque seria irrelevante ao mérito, na interpretação do discurso conservador, ou até mesmo significaria uma "ideologia doutrinária". Outros aspectos não menos importantes podem ser interpretados como tal. Por exemplo, problematizar o sexismo em práticas tradicionais que estabelecem lugares prévios para homens e mulheres seria passível de denúncia e de punição para os professores!

A partir do referido movimento, é possível que esta prática resulte em um processo por “ideologia de gênero" e que a anterior seja considerada uma manifestação doutrinária "marxistaleninista", expressão esta cunhada pelo deputado ao se referir à esquerda como um único bloco de pensamento. Para os defensores do MESP, qualquer discussão semelhante vai de encontro à pluralidade cultural, uma vez que, para eles, como dito antes, os alunos são "audiência cativa", submetidos a "ideólogos-docentes". Possivelmente prevendo algumas reações contrárias às suas teses, chegam a ponto de dizer que os alunos defendem os professores porque sofrem de "Síndrome de Estocolmo", em uma clara alusão à ideia de que o violentado se identifica que o violentador. No endereço eletrônico da página do movimento escola sem partido, podemos perceber ainda a defesa de que o professor não deve tratar de "determinados assuntos" nem mesmo fora da escola com os alunos. Assim, qualquer tentativa de contradizer os valores privados, seja na escola ou não, poderá ser denunciada como um crime ideológico.

Considerando o exposto, somos obrigados a retomar discussões já quase superadas por nós no campo da educação: um currículo neutro é possível? Haverá alguma coisa a ser dita em sala de aula que não foi dita em algum momento por mais alguém que contradiz a perspectiva e os valores

13 Confira projeto de lei do deputado Rogério Marinho do Rio Grande do Norte: <http://www.camara.gov. br/proposicoesWeb/prop_mostrarintegra;jsessionid=BEB1CB63A318970E767BC84B2FCFC47C.proposicoesWeb1?co dteor $=1435263 \&$ filename$=P L+4486 / 2016>$. Acesso em: 10/04/17. 
de outro? Considerando as diferenças de opinião, as discordâncias, os antagonismos, é possível que se diga apenas o que não se contradiz (em momento algum) com os valores ditos "da família"? Enfim, entendemos que a própria possibilidade da educação e do ensino fica colocada em questão.

Procuramos anteriormente analisar que a separação radical entre produção e implementação impõe ao professor o lugar de executor de funções técnicas, submetido a um conhecimento científico, supostamente dado e universal, produzido por outros. Na investida conservadora, tal ideia é levada ao extremo, pois o professor deverá ensinar exclusivamente o que está escrito no documento-guia, cabendo, inclusive espaço para sanções punitivas - além da responsabilização que uma avaliação por desempenho profissional pode encaminhar ${ }^{14}$.

Conforme destaca Andréa Gouveia em um recente debate no programa Salto para o Futuro $^{15}$, sabemos que o caminho para a BNCC não será freado, porém cabe a luta para não legitimá-la como uma lista de conteúdos específicos, mas como diretrizes gerais, dando subsídios para que as escolas continuem produzindo o currículo. "Se há problemas na formação, certamente haverá após a BNCC, pois os professores serão os mesmos”, destaca. Não será um documento obrigatório com conteúdos mínimos e uma lista de competências a panaceia do sistema educacional brasileiro, mas os efeitos já são bastante conhecidos por nós, por exemplo, a responsabilização docente. Deste modo, dialogamos com a ANPEd e a ABdC, bem como um grupo de pesquisadores brasileiros e internacionais que discutem currículo. Ressaltamos em uma só voz: não há qualidade viável para a educação sem que se valorizem os docentes e todos os profissionais da área, cujos salários e planos de carreira encontram-se defasados e inconsistentes com a sua atuação em cenário tão complexo.

Macedo (2014) lembra que a empreitada do então presidente Fernando Henrique Cardoso (FHC) nos anos 1990 foi destituída pelo CNE na época. O Conselho interpretou na ocasião que os PCN deveriam ser de caráter não obrigatório e não uma base como queria FHC. Considerando tais aspectos, a aludida pesquisadora argumenta que uma base pode ser possível em outros sentidos que não a normatividade de conteúdos específicos, além de ressaltar que no novo PNE ela está prevista como estratégia e não como uma meta, o que permite mudar o curso.

Nosso argumento em defesa da qualidade, portanto, não é projetar o currículo como salvação, tomando-o como objeto / como dado; mas entendê-lo como significação, como prática discursiva a cerca da sua própria representação. Ou seja, diferentes sentidos de currículo disputam o

\footnotetext{
${ }^{14} \mathrm{Cf}$. $\langle$ https://www.youtube.com/watch?v=-YjSBI9nNY8 $>$. Acesso em: 10/04/17.

${ }^{15}$ Disponível em: <http://tvescola.mec.gov.br/tve/video/salto-base-nacional-comum-curricular $>$. Acesso em: 10/04/17.
} 
que se entende como tal, articulando finalidades educativas e políticas distintas e antagônicas, as quais entendemos que precisam estar sempre explicitadas e discutidas.

Temos procurado entender como discursos particulares ganham status de universal, excluindo demandas sociais na tentativa de frear avanços importantes para os movimentos sociais, como a luta contra o racismo e contra a discriminação (BRASIL, 2005; JESUS, ARAÚJO e JÚNIOR, 2013). Ademais, pensamos que consiste em reducionismo e imposição política desconsiderar o "chão da escola" como a base por meio da qual a educação se faz contingencialmente, como contexto, lócus e ambiência de criação e não de reprodução do mesmo.

\section{UMA PAUSA À BEIRA DO CAMINHO}

Procuramos nos contrapor a diferentes discursos que articulam a BNCC como garantia de direitos e de qualidade da educação. Buscamos também demonstrar que nenhum dos termos em que a ideia de base se escora é passível de consenso universal, significando, portanto, uma operação de poder, cujos desdobramentos têm sido questionados em outros países, gerando problemas como a responsabilização docente, cujos efeitos na subjetividade docente ainda não foram objeto de muitos estudos.

Associando meritocracia, mito da democracia social e racial, avaliação de rendimentos em larga escola, índices de qualidade, formação para a competência, bem como outros termos da ideia mercadológica de eficiência/ eficácia, há a ameaça de vivenciarmos uma cultura da delação e do silêncio, movida por movimentos conservadores que fortalecem retrocessos. A disputa pela significação do mundo articula diferentes interesses, desejos, rastros de sentidos que reiteram histórias de opressão e discriminação, é claro, reatualizados.

Lembremos que a luta pela educação se fortalece na ampliação e no enfoque da discussão de algumas metas do próprio PNE. Por exemplo, destacamos a meta 18 que implica na valorização docente por meio do plano salarial e de carreira, por sinal, no mesmo prazo da alteração curricular. Também não imaginamos falar de qualidade sem pensar em políticas públicas locais, haja vista as demandas diversas. Na medida em que novas e antigas estratégias de articulação democráticas são postas em curso, em tempos de golpe de governo elas precisam de um cuidado maior. Temos assumido como parte de nossa luta política a desconstrução de valores impostos como absolutos, quando se tratam apenas de sentidos particulares buscando a hegemonia.

Consideramos ainda que o fortalecimento da profissão docente e das políticas públicas, a nosso ver, contribui com as demandas da diferença e vice-versa, já que muitas das lutas se cruzam e 
são mutuamente potencializadas como equivalências. Quando trazemos esta palavra não queremos dizer que são iguais, mas que podem articular questões frente a um antagonismo comum. Silenciar professores e responsabilizá-lo por um suposto fracasso é também vedar o debate em torno de muitas demandas.

Por uma questão de enfoque e limites, não enfatizamos os aspectos referentes ao ensino religioso na BNCC. No entanto, sugerimos pesquisas a respeito da temática. Trata-se de uma questão urgente para ser estudada e debatida. Seja considerando o risco da perda da liberdade de ensino, seja pela via religiosidade/ laicidade, as ameaças estão em jogo e não se dão apenas na esfera econômica. 


\section{REFERÊNCIAS}

ALVES, N. Sobre a possibilidade e a necessidade de uma base nacional comum. Revista E-Curriculum, São Paulo, v. 2, n. 3, p. 1464-1479, out./dez. 2014.

ANPED. Exposição de motivos sobre a Base Nacional Comum Curricular. Disponível em: http://www.anped. org.br/sites/default/files/resources/Of_cio_01_2015_CNE_BNCC.pdf. Acesso em: 24 de setembro de 2016.

BALL, S. J. Educação global S.A. Novas redes políticas e o imaginário neoliberal. Trad. Janete Bridon. Ponta Grossa: Editora UEPG, 2014.

BRASIL. Lei 10.639, de 09 de janeiro de 2003. Altera a Lei de Diretrizes e Bases da Educação Nacional 9.394/96 para incluir no currículo oficial da Rede de Ensino a obrigatoriedade da temática "História e Cultura Afro-Brasileira". Diário Oficial da União. Poder Legislativo, Brasília, 10 jan. 2003, p. 1.

Lei 13.005, de 25 de junho de 2014. Aprova o Plano Nacional de Educação - PNE. Diário Oficial da União. Poder Legislativo, Brasília, 26 jun. 2014, edição extra, p. 1.

BURBULES, N. C. Uma gramática da diferença: algumas formas de repensar a diferença e a diversidade como tópicos educacionais. In: GARCIA, R.L.; MOREIRA, A.F.B. (Orgs.). Currículo na contemporaneidade: Incertezas e desafios. 4. ed. São Paulo: Cortez, 2012. p. 175-206.

BURITY, J.A. Discurso, política e sujeito na teoria da hegemonia de Ernesto Laclau. In: MENDONÇA, D.; RODRIGUES, L. P. (Orgs.). Pós-Estruturalismo e Teoria do Discurso: em torno de Ernesto Laclau. Porto Alegre: EDIPUCRS, 2008. p. 35-52.

FREITAS, L. C. BNCC: sob nova direção. Disponível em: <https://avaliacaoeducacional.com/2016/05/31/bncc-sobnova-direcao/>.Acesso em: 24 set. 2016.

GARCIA, A.; FONTOURA, H. A. Guarda isso porque não cai na provinha”: pensando processos de centralização curricular, sentidos de comum e formação docente. Revista e-Curriculum. São Paulo, v. 13, n. 04, p. 751 -774 out./dez. 2015 .

JESUS, R.F.; ARAÚJO, M.S.; JUNIOR, H.C. (Orgs.). Dez anos da Lei 10.639/2003: memórias e perspectivas. Fortaleza: Edições UFC, 2013b. p. 131-148.

LACLAU, E. La razón populista. Buenos Aires: Fondo de Cultura Econômica, 2009.

LOPES, Alice Casimiro. Por um currículo sem fundamentos. Linhas Críticas (UnB), Brasília, v. 21, p. 445- 466, 2015.

; MACEDO, Elizabeth. Teorias de currículo. São Paulo: Cortez, 2011.

MACEDO, E. Por uma política da diferença. Cadernos de Pesquisa, v. 36, n. 128, maio/ago. 2006.

Como a diferença passa do centro à margem nos currículos: o exemplo dos PCN. Educ. Soc. Campinas, vol. 30, n. 106, p. 87-109, jan./abr. 2009.

Base Nacional Curricular Comum: novas formas de sociabilidade produzindo sentidos para educação. Revista E-Curriculum. São Paulo, v. 2, n. 3, p. 1530-1555, out./dez., 2014.

. Base Nacional Comum para currículos: direitos de aprendizagem e desenvolvimento para quem? Educ. Soc. Campinas, v. 36, n. 133, p. 891-908, out.-dez., 2015.

MILLER, J. L. Teorização do currículo como antídoto contra/ na cultura da testagem. Revista E-Curriculum. São Paulo, v. 2, n. 3, p. 2043-2063, out./dez. 2014.

PEREIRA, F.B.; OLIVEIRA, I.B. Ponderações ao currículo mínimo da rede estadual do Rio de Janeiro: uma contribuição ao debate em torno da base comum nacional. Revista E-Curriculum, São Paulo, v. 2, n. 3, p. 1669-1692, out./dez. 2014.

SUSSEKIND, M. L. As (im) possibilidades de uma base comum nacional. Revista E-Curriculum. São Paulo, v. 2 , n. 3, p.1512-1529, out./dez. 2014. 


\section{RESUMO}

Nesta produção apresentamos análises a respeito do projeto de implantação, em nosso país, da Base Nacional Curricular Comum Curricular, no sentido de uma lista de conteúdos específicos para a prática docente. Destacamos os argumentos utilizados por aqueles que a apresentam como indispensável à obtenção da unidade educacional, em especial os participantes do Movimento Escola Sem Partido, e elencamos problemas decorrentes desse objetivo, tais como a verificação de poucos espaços nesta proposta para questões prementes como cultura e diferença. Destacamos também alguns sentidos que vem sendo atribuídos ao projeto e ao currículo, enveredando para a verificação dos riscos que podem envolver uma centralização curricular.

Palavras-chave: Base Nacional Comum Curricular, Currículos, Diferença.

\section{DISPUTES BY THE COMMON CURRICULAR NATIONAL BASIS: THINKING OF DIFFERENCE AND EDUCATION}

\section{ABSTRACT}

In this production we present analyzes regarding the project of implantation in Brazil, of the National Curricular Common Curricular Base, in the sense of a list of specific contents for the teaching practice. We emphasize the arguments used by those who present it as indispensable to the achievement of the educational unit, especially the participants of the Movement Without a Party. We address problems arising from this objective, such as the verification of few spaces in this proposal for pressing issues such as culture and difference. We also highlight some of the meanings that have been attributed to the project and the curriculum. We analyze the problems that can occur from curricular centralization.

Keywords: National Common Curricular Base, Curriculum, Difference.

\section{DISPUTAS POR LA BASE NACIONAL COMÚN CURRICULAR: PENSANDO EN DIFERENCIA Y EN EDUCACIÓN}

\section{RESUMEN}

En esta producción presentamos análisis sobre el proyecto de implantación en Brasil, de la Base Curricular Común Curricular Nacional, en el sentido de una lista de contenidos específicos para la práctica docente. Destacamos los argumentos utilizados por quienes lo presentan como indispensables para el logro de la unidad educativa, especialmente los participantes del Movimiento Sin Partido. Abordamos los problemas que surgen de este objetivo, como la verificación de algunos espacios en esta propuesta para asuntos urgentes como la cultura y la diferencia. También destacamos algunos de los significados que se han atribuido al proyecto y al plan de estudios. Analizamos los problemas que pueden ocurrir a partir de la centralización curricular.

Palabras clave: Base Curricular Común Nacional, Curriculos, Diferencia. 